\title{
Liposome/Tat Complex for Facilitating Genistein Uptake into B16 Melanoma Cells
}

\author{
Young Mi Park, MyungJoo Kang, Ki Young Moon, Sang Han Park, \\ Mean Hyung Kang and Young Wook Choi ${ }^{\dagger}$ \\ Division of Pharmaceutical Science, College of Pharmacy, Chung-Ang University, \\ 221 Heuksuk-dong, Dongjak-gu, Seoul 156-756, Korea \\ (Received March 22, $2011 \cdot$ Revised March 29, $2011 \cdot$ Accepted July 1, 2011)
}

\begin{abstract}
Genistein (GT), a major isoflavone found in soybeans, has a potent antioxidant effect that protects the skin from UV-induced damages and malignant melanoma. In order to enhance the cellular uptake of GT, liposome/Tat complexes were prepared by an electrostatic interaction of anionic liposome (DMPC/DCP, 9:1 in molar ratio) with Tat peptide (0.02 to 0.08 mole), one of the well-known cell penetrating peptide (CPP). As the amount of Tat increased, the size increased but the zeta potential decreased. In vitro release study with dialysis membrane elicited GT release from liposomal preparations in a controlled manner. The addition of Tat increased GT release, especially for the initial period. In the cellular uptake study by incubating B16 melanoma cells with various liposomal preparations containing GT, B16 melanoma cells demonstrated a time-dependent increase of drug accumulation. Compared to the aqueous GT suspension, intracellular uptake was substantially enhanced by anionic liposomal formulation and further increased by the complex formulation. Therefore, liposome/Tat complex might be a good candidate for facilitating intracellular drug delivery.
\end{abstract}

Key words - Genistein, Liposome/Tat complex, B16 melanoma cell, Drug release, Cellular uptake

Among the various cancers cells, human melanoma cells are well-known to have less antioxidant capacity than that of normal melanocytes. Moreover, melanoma cells are capable of producing large amounts of superoxide anions without stimulants, which are implicated in metastasis by promoting endothelial injury (Ichihashi et al., 2000; Wei et al., 2003; Sander et al., 2004). Genistein (GT), one of the major isoflavones in Leguminosae, has been attractive because epidemiologic studies showed that consumption of soybean-containing diets was associated with a lower incidence of certain human cancers in Asian populations (Barnes et al., 1990). Such chemopreventive and antineoplastic effects of GT were related with the antioxidant activity and inhibitory activities on cell proliferation and angiogenesis (Spinozzi et al., 1994; Zhou et al., 1998; Booth et al., 1999; Vedavanam et al., 1999; Surh et al., 2001). However, due to poor solubility and poor permeability of GT, clinical applications are very limited (Rimbach et al., 2003; Motlekar et al., 2006). Oral bioavailability of GT has been extensively studied (Kwon et al., 2007).

One approach to circumvent the problem of low efficiency of cellular uptake is to incorporate peptides that are capable of penetrating the plasma membrane. Such peptides, called protein transduction domains (PTD) or cell-penetrating peptides

\footnotetext{
Corresponding Author :

Tel : +82-2-820-5609, E-mail : ywchoi@cau.ac.kr

DOI : 10.4333/KPS.2011.41.4.205
}

(CPP), are either derived from naturally occurring proteins or artificially designed peptides. A number of CPP have been successfully used to deliver drugs, protein and even DNA into cells (Hyndman et al., 2004). One of the shortest peptides containing a nuclear localization signal (NLS), Tat 48-60, was defined as the minimal translocating fragment (Temsamani and Vidal, 2004). These Tat peptides derived from the HIV type 1 Tat protein facilitate intracellular delivery of macromolecules and small colloidal particles.

Another way for increasing the delivery of drugs is the use of vesicular systems such as liposomes (Kang et al., 2010). Due to their biocompatibility and the capability of incorporating both hydrophilic and lipophilic drugs, liposomes are widely used as delivery systems for a broad spectrum of agents including chemotherapeutics, imaging agents, antigens, lipids and DNA (Martyet al., 2004). Moreover, therapeutic molecules are protected by the lipid bilayer of the liposome from metabolism and enzymatic degradation. It was also demonstrated that relatively large drug carriers, such as 200nm liposomes, can also be delivered into cells by Tat peptide attachment to the liposome surface (Torchilin et al., 2001).

Therefore, in the present study, liposome/Tat complexes have been developed for facilitating GT delivery into B16 melanoma cells. Along with physical characterization of the complexes, pharmaceutical evaluations for dispersion stability, in vitro drug release, and cellular uptake efficiency were performed. 


\section{Materials and Methods}

\section{Cell lines and cell culture}

The B16 melanoma cells were cultured in Dulbecco's modified Eagle's medium containing $20 \mathrm{mM}$ HEPES/ $\mathrm{NaOH}(\mathrm{pH}$ 7.4), $5 \mathrm{mM} \mathrm{NaHCO} 3,10 \%$ fetal bovine serum (FBS) and antibiotics $\left(100 \mu \mathrm{g} / \mathrm{mL}\right.$ streptomycin, $100 \mathrm{U} / \mathrm{mL}$ penicillin) at $37^{\circ} \mathrm{C}$ under a humidified condition of $95 \%$ air and $5 \% \mathrm{CO}_{2}$.

\section{Chemicals and reagents}

Genistein (GT) was provided from Rexgene Biotech Co. (Seoul, Korea). Dimyristoylphosphatidylcholine (DMPC), dicetylphosphate (DCP), stearylamine (SA), trypsin-EDTA, and N,Ndiethylnicotinamide (DENA) were purchased from Sigma Chemical Co. (St. Louis, MO, USA). Synthetic Tat peptide (Arg-Lys-Lys-Arg-Arg-Gln-Arg-Arg-Arg, 9mer) was purchased from Peptron Co. (Taejun, Korea). All other chemicals and reagents purchased from commercial sources were of analytical grade. Double distilled water was used for all experiments.

\section{Preparation of liposomesand liposome/Tat complexes}

Liposomes were prepared by conventional film hydration and extrusion method. Briefly,in case of a neutral liposome, DMPC was dissolved in chloroform and methanol mixture (3:2 v/v) along with $30 \mu \mathrm{M}$ of GT in a round bottom flask. DCP and SA were added to DMPC liposome in 9:1 molar ratio for preparing anionic and cationic liposomes, respectively. Solvent was removed by rotary vacuum evaporation above the lipid transition temperature (Rotary Evaporator, Super fit, Ambala, India) for approximately $30 \mathrm{~min}$, and solvent traces were removed by maintaining the lipid film under vacuum overnight at room temperature. Thin lipid films were then hydrated with double-distilled water by rotation (100 rpm, $40^{\circ} \mathrm{C}, 10 \mathrm{~min}$ ) and extruded ten times through sandwiches of $200 \mathrm{~nm}$ polycarbonate membrane filter (Millipore, USA) to obtain small unilamellar vesicles (SUVs). The final lipid concentrations in all vesicular formulations were approximately $14 \mathrm{mM}$

Formation of liposome/Tat complexes was carried out in aqueous dispersion at room temperature. Different amount of Tat was added to anionic liposomes and allowed to stand for $5 \mathrm{~min}$ for electrostatic complexation. The molar ratio of DMPC:DCP:Tat were 9:1:0.02 (Complex 1), 9:1:0.04 (Complex 2), and 9:1:0.08 (Complex 3). Complex 2 and complex 3 were re-extruded ten times through $400 \mathrm{~nm}$ polycarbonate membrane filters (Millipore, USA), unlikely to complex 1 in which the vesicular size was not changed significantly com- pared to that of anionic liposome.

\section{Measurement of vesicle size and zeta potential}

Physical characteristics of liposomes and liposome/Tat complexes including particle size and size distribution, polydispersity index, and zeta potential were determined by dynamic light scattering (DLS) method with Zetasizer Nano-ZS (Malvern Instrument, Worcestershire, UK). Liposomes and liposome/Tat complexes were diluted 10-fold with double-distilled water for the measurement in triplicates. The stability of liposome and liposome/Tat complexes was determined by comparing the particle size change over time.

\section{Determination of entrapment capacity}

The encapsulation efficiency was determined by ultracentrifugation method. Immediately after preparing liposomes and liposome/Tat complexes, the product was ultracentrifuged $\left(48,000 \mathrm{~g}, 4^{\circ} \mathrm{C}, 30 \mathrm{~min}\right)$ to separate the unincorporated drug. After ultracentrifugation, GT content in supernatant and pellet were assayed by HPLC. The entrapment capacity of liposomes and liposome/Tat complexes were calculated as follows: (T$\mathrm{C}) / \mathrm{T} \times 100$, where $\mathrm{T}$ is the total amount of drug in both the supernatant and pellet, and $\mathrm{C}$ is the amount of drugin thesupernatant.

\section{In vitro release test}

Release of GT from various liposomal formulations was determined at $37^{\circ} \mathrm{C}$ using Franz diffusion cell mounted with a dialysis membrane (MWCO $12 \mathrm{kDa}$ ). Phosphate buffer solution ( $\mathrm{pH}$ 7.4) containing DENA (1 M) was used as a receptor medium for sink condition. GT solution in 10\% DMSO, liposomal suspension, liposome/Tat complexes, and aqueous GT suspension were loaded to donor compartment. At predetermined time points, an aliquot $(500 \mu \mathrm{L})$ of receptor solution was withdrawn and assayed for GT by HPLC analysis.

\section{Cellular uptake of GT}

B16 melanoma cells were seeded at the density of $1 \times 10^{5} /$ well to 6-well dish. After $12 \mathrm{hr}$, the cells were incubated with GT suspension, liposomal suspension, liposome/Tat complexes. The incubationwas stopped by washing the cells with ice-cold PBS (Wang et al., 2005). The cells were harvested by $1 \mathrm{x}$ trypsin-EDTA solution and collected by centrifugation at $20,000 \mathrm{~g}$ for $5 \mathrm{~min}$. The supernatants were removed and resulting pellets were re-suspended in 1.0 mLPBS. Suspended cells were lysed by sonication (3/1 s, 200W, 10 times) and then centrifuged at $20,000 \mathrm{~g}$ for $5 \mathrm{~min}$. The supernatants were transferred to test tube and extracted with $5 \mathrm{~mL}$ ethyl acetate. The 
mixture was vortexed for $30 \mathrm{~min}$ and then centrifuged for 15 min at $4000 \mathrm{~g}$. The upper layer was transferred into another test tube and evaporated to dryness with $\mathrm{N}_{2}$ stream at $35^{\circ} \mathrm{C}$. The residue was reconstituted in $150 \mu \mathrm{L}$ of $50 \%$ methanol and vortexed for $3 \mathrm{~min}$. An aliquot $(50 \mu \mathrm{L})$ of the solution was injected into the HPLC system for GT assay.

\section{GT assay by HPLC}

The concentration of GT was determined by HPLC. The HPLC system consisted of a pump (L-2130), an UV detector (L-2400, $\lambda=262 \mathrm{~nm}$ ), a data station (LaChrom Elite, Hitachi, Japan), and a $\mathrm{C}_{18}$ column (15 cm, Shiseido ${ }^{\mathrm{TM}}$, Japan). The mobile phase comprised acetonitrile $/ 50 \mathrm{mM}$ ammonium formate buffer solution $(4: 6 \mathrm{v} / \mathrm{v})$ and was delivered at a flow rate of $1 \mathrm{~mL} / \mathrm{min}$. The injection volume was $50 \mu \mathrm{L}$ and the relative retention time was found to be $4.5 \mathrm{~min}$.

\section{Results and Discussion}

\section{Characterization of liposomes and liposome/Tat com- plexes}

To investigate the effect of Tat complexation, Tat was added to anionic liposome in various molar ratios from 0.02 to 0.08 versus DCP content. Vesicular size of anionic liposome was greatly increased by the complexation, revealing the linear relationship between the size and Tat content (data not shown). The size of the complex 1 (Tat ratio of 0.02) was kept in similar range to that of anionic liposome. Beyond this ratio, the vesicles were larger than $2 \mu \mathrm{m}$ requiring further size reduction. Therefore, complexes 2 and 3 were prepared by re-extrusion through $400 \mathrm{~nm}$ polycarbonate membrane filter. As a result, all liposome/Tat complexes were in the range of 210 to $320 \mathrm{~nm}$ in average, a little greater than those of neutral or charged liposomes (Table I). Low polydispersity index of less than 0.3 indicates a narrow and homogeneous size distribution of all liposomal formulations.

Surface charge of liposomes can be manipulated by the addition of charged molecules into the bilayer. Anionic liposome was successfully prepared with DMPC and DCP, having a zeta potential of about $-45 \mathrm{mV}$. By the addition of Tat, a positively charged peptide, the potential of the complexes was decreased proportionally to Tat content. This is an evidence for electrostatic interactions between anionic liposome and Tat peptide to form a complex, and Tat is mostly located at the surface of the complexes as depicted in Figure 1. On the other hand, GT was efficiently loaded into liposomes and liposome/Tat complexes, revealing high entrapment capacity of over $80 \%$ in all liposomal formulations. Tat complexation of the anionic liposome did not change the entrapment efficiency of the vesicle, suggesting that the bilayer function was maintained intact and the drug was efficiently encapsulated within the vesicle.

\section{Dispersion stability of liposome/Tat complexes}

Aqueous dispersion of liposomal vesicles is stabilized by an appropriate zeta potential, an electric repulsion at shear plane of the particle. Therefore, surface charge including zeta poten-

Table I. Physical characteristics of GT-loaded liposomes and liposome/Tat complexes

\begin{tabular}{|c|c|c|c|c|c|c|}
\hline \multirow{2}{*}{ Parameters } & \multicolumn{3}{|c|}{ Liposome } & \multicolumn{3}{|c|}{ "Liposome/Tat Complex } \\
\hline & Neutral & Cationic & Anionic & Complex 1 & Complex 2 & Complex 3 \\
\hline Mean vesicular size (nm) & $159.1 \pm 6.1$ & $174.6 \pm 4.4$ & $194.0 \pm 3.3$ & $212.8 \pm 6.9$ & $239.3 \pm 6.1$ & $318.8 \pm 20.3$ \\
\hline Polydispersity index & $0.13 \pm 0.06$ & $0.18 \pm 0.06$ & $0.23 \pm 0.04$ & $0.19 \pm 0.08$ & $0.28 \pm 0.01$ & $0.26 \pm 0.03$ \\
\hline Zeta potential $(\mathrm{mV})$ & $-14.3 \pm 0.3$ & $+47.4 \pm 0.6$ & $-45.4 \pm 1.6$ & $-38.8 \pm 2.3$ & $-27.2 \pm 0.8$ & $-15.9 \pm 0.9$ \\
\hline Entrapment capacity (\%) & $81.4 \pm 3.1$ & $80.9 \pm 1.5$ & $81.9 \pm 5.5$ & $83.8 \pm 3.8$ & $84.1 \pm 2.1$ & $82.9 \pm 1.0$ \\
\hline
\end{tabular}

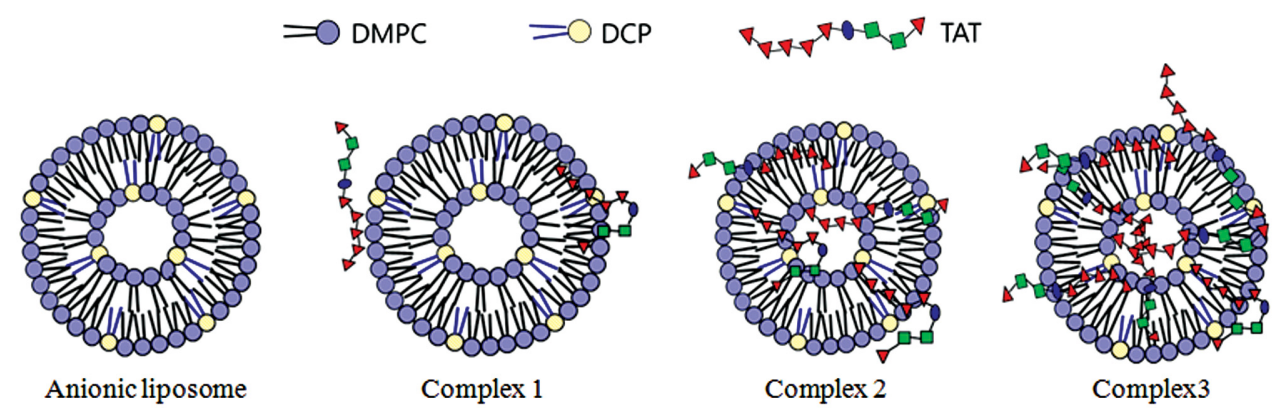

Figure 1. Drawing illustrations of anionic liposome and liposome/Tat complexes. 


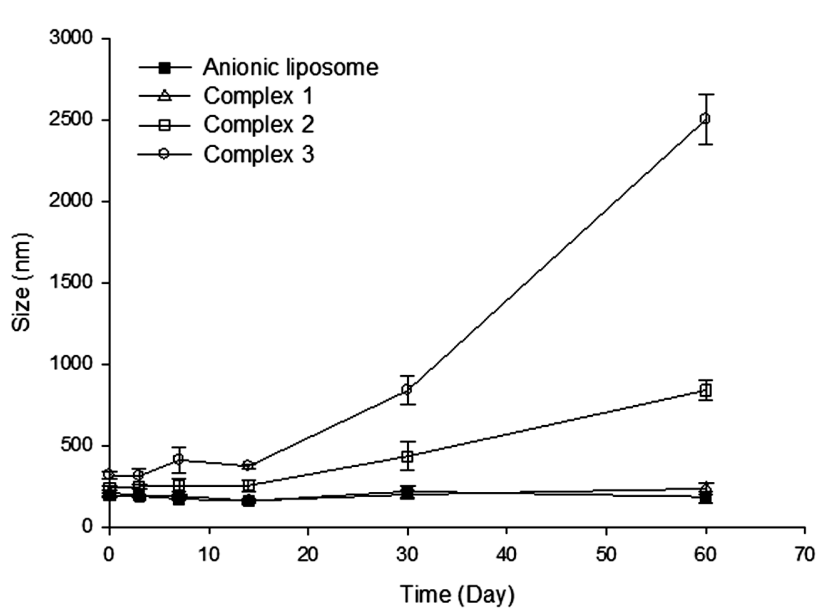

Figure 2. Dispersion stability of liposome and liposome/Tat complexes on storage at 4 for 60 days.

tial plays a major role for stable dispersion of the vesicles without any aggregation or caking. Physical dispersion stability of anionic liposome and liposome/Tat complexes was determined by the observation of the particle size changes over time. On storage for 60 days at $4^{\circ} \mathrm{C}$, as shown in Figure 2, anionic liposome and complex 1 did not show any significant changes in vesicle size. Greater zeta potential (about $-40 \mathrm{mV}$ ) of both liposomal systems contributed to protect the vesicles from the aggregation of the dispersed phases. Meanwhile, the size of the complexes 2 and 3 was greatly increased upon storage. This might be due to the weaker zeta potential of the complex 2 $(-27 \mathrm{mV})$ and complex $3(-16 \mathrm{mV})$, resulting in closer contact of the particles. Therefore, fresh liposomal preparations were further used for the drug release and cellular uptake study, since all liposomal preparations were stable enough for the first two weeks of storage.

\section{In vitro release of GT}

To evaluate the drug release property of liposome/Tat complexes, other samples of GT solution in 10\% DMSO, liposomal suspension, and aqueous GT suspension were compared (Figure 3). Since the release studies were carried out with a receptor medium offering sink condition for GT, solubilized or unencapsulated drug can be diffused freely through a dialysis membrane. The solubility of GT in water was estimated as $3.04 \mathrm{ng} / \mathrm{mL}$ in earlier report (Motlekar et al., 2006). By adding DENA as a hydrotropic agent, GT is very soluble in aqueous receptor medium to provide a sink condition.GT solution brought the fastest release in the earlier stage of release and reached equilibrium afterward. Drug release from aqueous GT suspension was very low, due to its limited solubility in water.

GT was released from liposomal suspension in a controlled

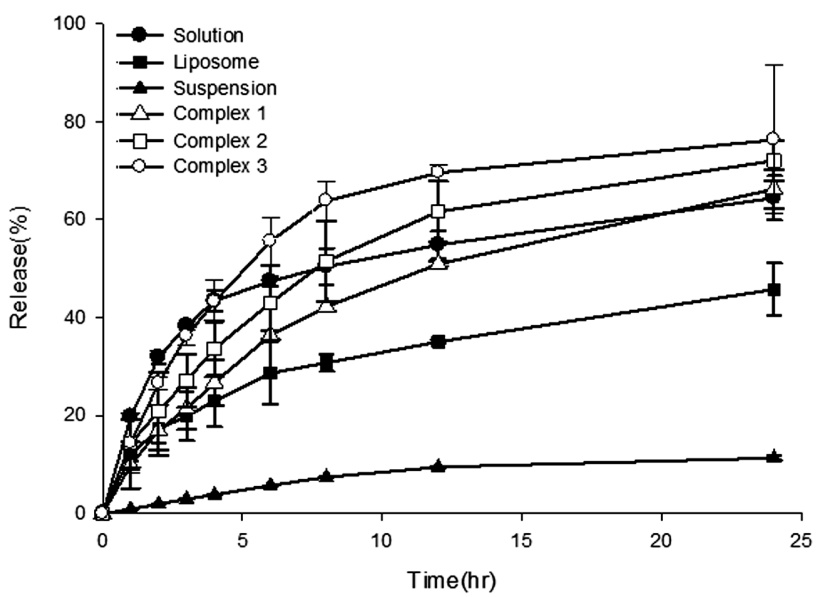

Figure 3. In vitro release of GT from various preparations.

manner. The addition of Tat peptide increased GT release, especially for the initial period. As the amount of Tat increased, the release of GT increased as well. Overall order of release was decreased as follows: Complex $3>$ Complex $2>$ Complex $1>$ Anionic liposome. The reason for this phenomenon can be explained by two possibilities. First, Tat addition perturbs the bilayer structure and thereby makes the liposome leaky. Even though the positively-charged peptide binds to the negative charge at the surface, some fragments of Tat peptide sequence could penetrate the liposomal membrane by virtue of its cell penetrating capability in living cells. Secondly, reorientation of Tat peptide may occur, anchoring the hydrophobic domain of the peptide into the bilayer. Complexes 2 and 3 were originally large in vesicle size, and subjected to re-extrusion through $400 \mathrm{~nm}$ polycarbonate membrane filter. During this procedure, the bilayer could be re-assembled with a structure of most Tat peptides orienting outwards and some peptides locating at inner compartment or within the lamellae.

\section{Effect of liposome/Tat complex on cellular uptake of GT}

Facilitation of cellular uptake was evaluated by incubating B16 melanoma cells with various liposomal preparations containing GT. In the present study, the cold PBS was used to wash cells in order to remove free GT adhering to the cell membranes after incubation. After pretreatment, the values measured by the HPLC assay reflected the amount of GT that was taken up by the B16 melanoma cells. The results for intracellular drug accumulation in B16 melanoma cells after 2, 4 and $6 \mathrm{hr}$ incubation with various preparations including aqueous GT suspension, anionic liposome, and liposome/Tat complexes are shown in Figure 4.

B16 melanoma cells demonstrated a time-dependent increase of drug accumulation in all preparations tested. These results 


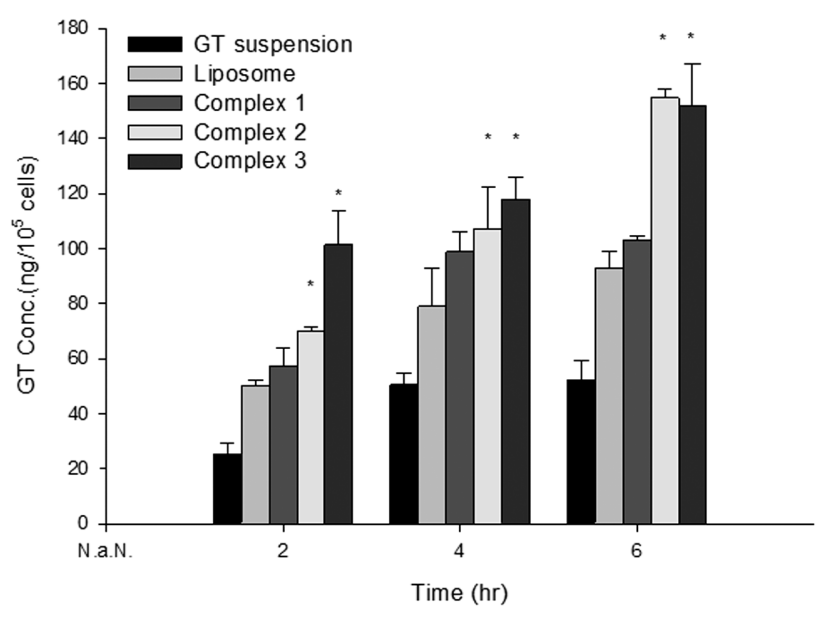

Figure 4. Intracellular drug accumulation in B16 melanoma cells after incubation with various preparations. Results are expressed as the amount of GT $/ 10^{5}$ cells. Statistical analysis was performed using the Student's t-test $\left({ }^{*} \mathrm{P}<0.05\right.$ versus liposome).

indicated that cells exposed to anionic liposome showed more pronounced accumulation than cells exposed to aqueous GT suspension. The intracellular uptake of GT was saturated within $6 \mathrm{hr}$ for the case of GT suspension, because of the low solubility of GT in distilled water. In comparison to GT suspension, intracellular uptake was substantially enhanced by anionic liposomal formulation. It was further increased by liposome/Tat complex formulations. These results are explained by the following reasons. First of all, drug release was greater in liposome/Tat complexes due to their leaky structures. The passive diffusion of GT through the cell membrane could be facilitated. In addition, the encapsulation of drug within CPP-modified liposome resulted in uptake enhancement of drug into cells. Tat peptide originally has the characteristics of penetration effect on cell membranes because of the ability to interact with lipid membranes and to adopt a significant secondary structure (Marty et al., 2004). Therefore, liposome/Tat complex might be a good candidate for facilitating intracellular drug delivery.

\section{Conclusion}

In the present study, the effect of Tat peptide complexation with anionic liposome on intracellular delivery of GT was investigated. Liposome/Tat complexes were characterized by physical properties of size distribution, zeta potential, and entrapment capacity. Dispersion stability, in vitro drug release, and cellular uptake efficiency were also evaluated. Finally, we could suggest that the liposome/Tat complex was superior to other conventional liposomes for intracellular delivery of GT.

\section{Acknowledgements}

This research was supported by Basic Science Research Program through the National Research Foundation (NRF) funded by Ministry of Education, Science and Technology(20110009876).

\section{References}

Barnes, S., Grubbs, C., Setchell, K.D., Carlson, J., 1990. Soybeans inhibit mammary tumors in models of breast cancer. Prog. Clin. Biol. Res. 239-253.

Booth, C., Hargreaves, D.F., Hadfield, J.A., McGown, A.T., Potten, C.S., 1999. Isoflavones inhibit intestinal epithelial cell proliferation and induce apoptosis in vitro. Br. J. Cancer 80, 15501557.

Hyndman, L., Lemoine, J.L., Huang, L., Porteous, D.J., Boyd, A.C., Nan, X., 2004. HIV-1 Tat protein transduction domain peptide facilitates gene transfer in combination with cationic liposomes. J. Control. Rel. 99, 435-444.

Ichihashi, M., Ahmed, N.U., Budiyanto, A., Wu, A., Bito, T.,Ueda, M., Osawa, T., 2000. Preventive effect of antioxidant on ultraviolet-induced skin cancer in mice. J. Dermatol. Sci. 23, S45S50.

Kang, M.J., Eum, J.Y., Jeong, M.S., Choi, S.E., Park, S.H., Cho, H.I., Cho, C.S., Seo, S.J., Lee, M.W., Choi, Y.W., 2010. Facilitated skin permeation of oregonin by elastic liposomal formulations and suppression of atopic dermatitis in $\mathrm{NC} / \mathrm{Nga}$ mice. Biol. Pharm. Bull. 33, 100-106.

Kwon, S.H., Kang M.J., Huh J.S., Ha, K.W., L, J.R., Lee, S.K., Lee, B.S., Han, I.H., Lee, M.S., Lee, M.W., Lee, J., Choi, Y.W., 2007. Comparison of oral bioavailability of genistein and genistin in rats. Int. J. Pharm. 337, 148-154.

Lee, K.W., Lee, H.J., 2006. The roles of polyphenols in cancer chemoprevention. Biofactors 26, 105-121.

Marty, C., Meylan, C., Schott, H., Ballmer-Hofer, K., Schwendener, R.A., 2004. Enhanced heparan sulfate proteoglycanmediated uptake of cell-penetrating peptide-modified liposomes. Cell. Mol. Life Sci. 61, 1785-1794.

Motlekar N., Khan, M.A., Youan, B-B.C., 2006. Preparation and characterization of genistein containing poly(ethylene glycol) microparticles. J. Appl. Polym. Sci. 101, 2070-2078.

Rimbach, G., De Pascual-Teresa, S., Ewins, B.A., Matsugo, S., Uchida, Y., Minihane, A.M., Turner, R., VafeiAdou, K., Weinberg, P.D., 2003. Antioxidant and free radical scavenging activity of isoflavone metabolites. Xenobiotica 33, 913-925.

Sander, C.S., Chang, H., Hamm, F., Elsner, P., Thiele, J.J., 2004. Role of oxidative stress and the antioxidant network in cutaneous carcinogenesis. Int. J. Dermatol. 43, 326-335.

Spinozzi, F., Pagliacci, M.C., Migliorati, G., Moraca, R., Grignani, F., Riccardi, C., Nicoletti, I., 1994. The Natural Tyrosine Kinase Inhibitor Genistein Produces Cell-Cycle Arrest and Apoptosis in Jurkat T-Leukemia Cells. Leuk. Res. 18, 431-439. 
Surh, Y.J., Chun, K.S., Cha, H.H., Han, S.S., Keum, Y.S., Park, K.K., Lee, S.S., 2001. Molecular mechanisms underlying chemopreventive activities of anti-inflammatory phytochemicals: down-regulation of COX-2 and iNOS through suppression of NF-kappa B activation. Mutat. Res. 480, 243-268.

Temsamani, J., Vidal, P., 2004. The use of cell-penetrating peptides for drug delivery. Drug Discovery Today 9, 1012-1019.

Torchilin, V.P., Rammohan, R., Weissig, V., Levchenko, T.S., 2001. TAT peptide on the surface of liposomes affords their efficient intracellular delivery even at low temperature and in the presence of metabolic inhibitors. Proc. Natl. Acad. Sci. U. S. A. 98, 8786-8791.

Vedavanam, K., Srijayanta, S., O'Reilly, J., Raman A., Wiseman, H., 1999. Antioxidant action and potential antidiabetic prop- erties of an isoflavonoid-containing soyabean phytochemical extract (SPE). Phytother. Res. 13, 601-608.

Wang, Y., Cao, J., Weng J.H., Zeng, S., 2005. Simultaneous determination of quercetin, kaempferol and isorhamnetin accumulated human beast cancer cells by high-performance liquid chromatography. J. Pharm. Biomed. Anal. 39, 328-333.

Wei, H., Saladi, R., Lu, Y., Wang, Y., Palep, S.R., Moore, J., Phelps, R., Shyong, E., Lebwohl, M.G., 2003. Isoflavone genistein: Photoprotection and clinical implications in dermatology. J. Nutr. 133, 3811S-3819S.

Zhou, J.R., Mukherjee, P., Gugger, E.T., Tanaka, T., Blackburn, G.L., Clinton, S.K., 1998. Inhibition of murine bladder tumorigenesis by soy isoflavones via alterations in the cell cycle, apoptosis, and angiogenesis. Cancer Res. 58, 5231-5238. 